\title{
Naive physics vs compositionality in evaluating the Lexical Aspect Hypothesis
}

\author{
Henk J. Verkuyl \\ Utrecht University
}

It will be argued that the LAH suffers from being based on the naive physics originating from ordinary language philosophers, who practiced ontology rather than doing semantics. Their metaphysics turns out to be incompatible with the principle of compositionality. Due to them a verb has been taken as a predicate rather than as a linguistic unit with its own lexical meaning. Therefore the leniency of a verb in the sense of being available for a wide variety of arguments has been underestimated.

Keywords: tense, aspect, compositionality, index, verb stem, actualization, anteriority, synchronous, terminativity, discretization

\section{Introduction}

The title of my contribution to the Leiden SLA-congress was Theoretical Pitfalls for SLA-research into tense, modality and aspect. The list of pitfalls is so long that it turned out to be impossible to discuss them sufficiently in detail within the permitted space. Therefore the present paper will discuss the theoretical foundation of the Lexical Aspect Hypothesis (LAH) at a more general level. ${ }^{1}$ This allows to focus on unfounded metaphysical assumptions forming the basis for the LAH and to reflect on what a strict compositional approach could mean for L2-research.

Salaberry (2000, 2003, p. 561) captures the essence of the LAH as proposed in Andersen and Shirai (1996) by the following four points.

1. Learners use perfective past marking (e.g., a preterit form) first on telic events, and they later extend its use to verbs from other lexical aspectual classes.

1. The congress title will now be used for a joint paper with Paz González in which the L2-literature on the LAH will be taken into account in much more detail. 
2. The imperfective marker (e.g., imperfect) will appear later than the preterite in association with atelic events (states and activities), eventually extending to telic events.

3. The use of the periphrastic progressive will initially appear in association with activity verbs and then extend to telic events.

4. The use of the periphrastic progressive will not overextend to stative verbs.

This formulation of the LAH reveals some theoretical assumptions underlying it: in all four points, the assumption that tense forms can be systematically connected with event classes; in 1 and 2, the assumption for Spanish that its pretérito is a perfective past tense rather than a pure tense form without explicitly expressing aspect; and in 3 and 4, the assumption for English that its periphrastic progressive is a potentially universal tense form rather than a peculiarity of English. It is at the level of these assumptions that I will argue against the weak theoretical foundation of the LAH.

The argumentation begins with the observation that there are three metaphysical forces having seduced theoretical linguists into taking (everyday) physics as the foundation for their semantic analyses:

A. the revival of Aristotelian ontology in ordinary language philosophy by Ryle $(1949,1954)$, Vendler (1957) and Kenny (1963) and its acceptance by linguists, as in Dowty (1979);

B. the technically attractive enrichment of ontology in the event semantics proposed by Davidson (1967) on the basis of Reichenbach (1947);

C. the apparent naturalness of the (naive-) physical tense tripartition into Past Present - Future, mainstream in formal semantics ever since Reichenbach (1947) and Prior (1967).

The present paper argues that a naive-physical perspective on the study of tense and aspect in the past decennia has inevitably been advanced at the cost of compositionality as a linguistic principle governing the construal of phrasal meaning from elementary parts. This has put the LAH on the wrong footing. Compositionality requires semantically that the contribution of a verb to a phrasal meaning be established after the "non-aspectual noise" coming from information about its arguments has been reduced to zero. This is done in $\S 2$, after which the way is open for opposing compositionality to the three forces mentioned in $\mathrm{A}, \mathrm{B}$ and C. As to the assumption underlying $1-4, \S 3$ argues that Vendler classes are mere ontological categories, the cult of which blocks a linguistic view on compositionality. In $\S 4$, it will be shown that a binary organization of a tense system renders the preterit in Romance languages peripheral: perfectivity and anteriority should be sharply distinguished. $\S 5$ claims that points 3 and 4 of the LAH are irrelevant given a rejection of $\mathrm{A}$ and $\mathrm{C}$ and a technical adaptation of $\mathrm{B}$. 
My position with respect to $\mathrm{A}-\mathrm{C}$ is a (cognitive) formal semantic one. Typelogical technicalities necessary for proving that compositionality can be achieved have been reduced to practically zero by the use of only elementary set theoretical notations, as informally as possible. These notations can hardly be evaded in dealing with intervals and tense structure. I refer to Verkuyl (2019) for all relevant technical details.

\section{At the bottom of a predication}

The line of thought followed here starts on the assumption that a tensed sentence $S^{\prime}$ is formed by combining a (possibly complex) tense-operator TENSE with the infinitival stem of a verb which is part of a tenseless predication S. Decoupling a verb stem expressing infinitiness and an inflectional element expressing finiteness is near standard in theoretical linguistics, for example in the form of (1). ${ }^{2}$

(1) $\left[{ }_{S} \ldots\right.$ TENSE $\left.\ldots\left[{ }_{S} \ldots\left[{ }_{\mathrm{VP}} \mathrm{V}_{\text {inf }} \ldots\right]\right]\right]$

The leading assumption behind this requires a compositional mechanism responsible for construing the infinitival $\mathrm{V}$ and the tense-operator into a unit expressing finiteness at the level of $S$. This assumption also holds implicitly in didactic grammars, which separate finite forms of a verb from its infinitive.

Surprisingly, the semantic contribution of the stem $V_{\text {inf }}$ to forming the (still) tenseless VP has hardly got the attention it deserves. In Dowty (1979), Smith (1991), Verkuyl (1993), Rothstein (1998), Binnick (2012), the last mentioned work is the only one with the term infinitive in its Index, with just one occurrence. Explicit attention for the semantics of $\mathrm{V}_{\text {inf }}$ itself as part of a compositional process is given in Verkuyl (2019). The present section aims at clarifying this semantics in order to show how blurred the glasses of naive physics as polished by Ryle $(1949,1954)$, Kenny (1963) and Vendler (1957) in fact turn out to be when it comes to the linguistic study of aspectuality.

Empirically, it is easy to see that the infinitival form of verbs like sail, be, walk, sit, lie, abstain, burn, exist, etc. captures situations which are not or cannot be bounded, so that in principle they can hold eternally. In the literal sense, that is, because one can use verbs like sing, sail and burn not only for talking about earthly situations but also for domains in which eternity is assumed, as in $(2 a)-(2 c)$.

2. I will use the term infinitival form for what may be called a verb stem or root. What I have in mind here is the form of a verb in the lexical entry of a mental lexicon. This is not a finite verb form. 
(2) a. Chosen ones are predestined to sing eternally to the honour of God.

b. The Flying Dutchman was doomed to sail across the oceans forever.

c. You will burn in hell for eternity.

d. When EFT bans an IP address, it can ban it permanently.

e. He promised to abstain from alcohol forever.

In all cases, including the mundane (2d) and (2e), a plausible way to model what is shared in the meaning of the underlined verbs is to picture it as involving a continuous and dense interval along the real number axis, i.e. as the interval $[0, \infty)$, which is $\mathbb{R}^{+}$on the assumption that there is no time axis in a (mental) lexicon.

$\stackrel{\vdash}{0}$

Figure 1. Continuity in $\mathbb{R}^{+}$

It is possible to interpret $(2 \mathrm{a})-(2 \mathrm{c})$ in terms of Figure 1 but given the nature of our projection from the real world to fictitious or possible worlds and our terrestial way of using verbs, we should not expect the ones who are chosen to sing eternally, to do that without any break. After all, Heine's/Wagner's Flying Dutchman was allowed after each seven years of sailing to go ashore for some time in order to free himself from the curse which made him sail forever. In the case of (2c), one should also allow Satan to put the burner into the zero-position for a while to raise devilishly the unjustified hope that the burning would stop forever. We cannot escape easily from our sublunary experience with people who sing, sail or burn eternally. ${ }^{3}$

The possibility to break up the continuous interval in Figure 1 into continuous finite subintervals for verbs like sing, sail and burn allows for a pictural representation as given in Figure 2, where the fat line indicates actualization (a sing-, sailor burn-interval), the thin line marks the absence of actualization.

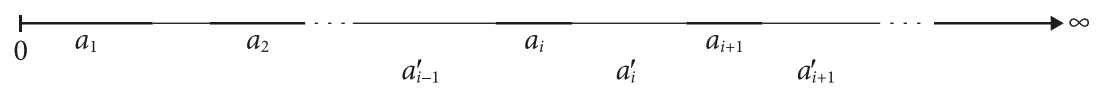

Figure 2. Irregular or periodical actualization in $\mathbb{R}^{+}$

3. In order for us to talk about speaking elephants in a fairy tale, the only thing we have to do is to change one feature in the noun elephant. The Flying Dutchman obtains immortality by a change of [+mortal] into [-mortal]. In our excursions from our real world into possible worlds, there is not much room for changes in properties and relations expressed by verbs and prepositions. 
In terms of the verb denotations discussed so far, two sets can be distinguished: (a) the set $A_{c}$ of intervals $a$ in $\mathbb{R}^{+}$in which the denotation of a predicate is actualized and (b) the set $A^{\prime}$ of intervals $a^{\prime}$ located between the intervals $a$ and not actualized as $a$-intervals. In other words, $A_{c}=\left\{a_{1}, a_{2}, \ldots\right\}$ and $A_{c}^{\prime}=\left\{a_{1}^{\prime}, a_{2}, \ldots\right\}$ such that $A_{c} \cup A_{c}{ }^{\prime}=\mathbb{R}^{+}{ }^{4}$ This means that Figure 1 is a particular instance of Figure 2, because if $A_{c}{ }^{\prime}=\varnothing$, it follows that $A_{c} \cup \varnothing=\mathbb{R}^{+}$. This is a crucial feature of the infinitival form of the underlined verbs in (2): they allow for just one unbounded interval equal to $\mathbb{R}^{+}$or for an unbounded series of finite subintervals of $\mathbb{R}^{+}$separated from each other by $a^{\prime}$-intervals. This property of underspecification makes these verbs suitable for being used for token reference and for type reference.

The underspecification inherent to the underlined verbs in (2) cannot be attributed to verbs requiring a different form of actualization: erupt, tick, blink, die, stumble, etc. They obey the restriction: $A_{c}{ }^{\prime} \neq \varnothing$. This is not an innocent matter in spite of the minimal difference with the verbs occurring in Figures 1 and 2: it amounts to requiring for each $a$ that there be an $a$ ' following it. This requirement has a set-theoretical formulation: for each a $\in A_{c}$, there is a positive number $m$ such that for all $\mathrm{x} \in a, x \leq m$. This makes $a$ bounded in the strict mathematical sense on the assumption that $a$ is a finite interval. But this is not sufficient: each of the sailing-intervals in the Heine/Wagner version of the Flying Dutchman in (2b) was also bounded. Verbs like erupt, tick, blink, die, stumble, etc. need an extra requirement: the positive number $m$ in $x \leq m$ is a natural number. In that way, one obtains a set of intervals $A_{d}$, where $A_{d} \subseteq \mathbb{N}$.

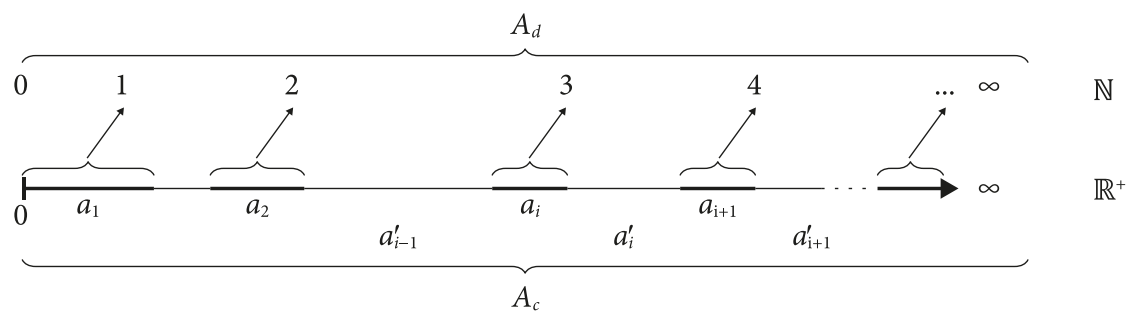

Figure 3. Discretization: Mapping into $\mathbb{N}$

4. More precisely: (i) $A_{c}=\left\{a_{i} \subseteq \mathbb{R}^{+} \mid\right.$for all $\left.a_{i}, a_{i+1}, a_{i} \cap a_{i+1}=\varnothing \& a_{i}<a_{i+1}\right\}$; and (ii) $\left.A_{c}{ }^{\prime}=\left\{a_{i}{ }^{\prime} \subseteq \mathbb{R}^{+} \mid \text {for all } a_{i}{ }^{\prime}, a_{i+1}, a_{i}{ }^{\prime} \cap a_{i+1}{ }^{\prime}=\varnothing \& a_{i}{ }^{\prime}<a_{i+1}\right)^{\prime}\right\}$. The relation between the two sets is defined by: $a_{i}<a_{i}{ }^{\prime}<a_{i+1}<a_{i+1}{ }^{\prime}$ : between the intervals $A_{i}$ and $a_{i+1}$ there is always just one interval $A_{i}$, which is an element of the set $A_{c}$ ' of intermittent intervals. When the members of $A_{c}$ ' have the same length, one may say that the members of $A_{c}$ appear periodically, otherwise they occur irregularly. The subscript $c$ is used to mark the difference between continuous $(c)$ and discrete $(d)$. 
Figure 3 captures how $A_{d}$ relates to $A_{c}$. Actualization of an interval takes place in $\mathbb{R}^{+}$so that one obtains a structure similar to the one in Figure 2 but a positive natural number $m$ requires a mapping into the set of discretely ordered numbers $\mathbb{N}$ made visible in the upper part of Figure 3. This mapping can be seen in terms of a rounding off function which differs from the standard one by disrespecting the equidistance between natural numbers. This so-called generalized ceiling function $g c$ is defined in Verkuyl (2019). I refer to the technicalities of that paper though an informal appeal to it will be made in $\S 3$ in order to make Figure 3 more perspicuous. This figure is important for seeing that all members of $A_{d}$ are anchored in the reals.

All verbs in a mental lexicon are covered by the sets $A_{c}$ and $A_{d}$ : they all express unboundedness, either in $\mathbb{R}^{+}$or in $\mathbb{N}$. We are analyzing here what is being expressed by verbs without any argument involved: their actualization is modeled by lexically assigning to them a set $A_{c}$ of one or more intervals in the real number system based on $A_{c} \cup A_{c}{ }^{\prime}=\mathbb{R}^{+}$. ${ }^{5}$ A subset of $A_{c}$ can form the input to the function $g c$ thus yielding the set $A_{d}$. Only at a higher structural level the unboundedness of $A_{c}$ and $A_{d}$ can be restricted by information contributed by the arguments of the verbs or by other information (adverbials, particles, etc.). Otherwise the context determines the choice between token and type reference. With an eye on (1), one may say that $\mathrm{V}_{\text {inf }}$ exactly does what has been described above: to express unboundedness at the type level which can only be prevented by finding a value $m$ providing boundedness at the token level of concrete actualization.

\section{Verb classes}

Apart from the distinction between continuous and discrete discussed above, there is another fundamental distinction between verbs without taking into account their arguments. Verkuyl (2019) provides a detailed description and justification of two functions modeling the distinction between stative and nonstative verbs. Here they are given informally. For stative verbs, the identity function id does the job with the definition: for all $x, i d(x)=x+b$, where $b=0$. This accounts for verbs like sleep, hang, lie, sit, be, ban, etcetera. Nonstative verbs can be characterized in terms of a function $s u$ having its domain and codomain in $\mathbb{R}$ defined

5. For those who believe in a unique life without resurrection, the verb die will be associated with a singleton in $a$ due to the restriction $\left|A_{d}\right|=1$. People believing in reincarnation use the verb die on the lexically fixed assumption of $A_{d}$ having a cardinality greater than 1 . A way for settling a dispute on this matter is: $A_{c} \cup A_{c}{ }^{\prime} \subseteq \mathbb{R}^{+}$ 
as: for all $x, s u(x)=x+b$, where $o<b \leq 1$. The property of unboundedly expressing progress defined here in terms of $s u$ was abbreviated as [+ADDTO] in Verkuyl (1993). It comes closer to the Galilean concept of movement in which movement is seen as unbounded unless there is some external force bringing movement to a stop rather than to the Aristotelian one which says that every movement has a telos, a goal.

The difference between the two functions is sufficient for making a distinction between the sense of the absence of change and the sense of progress, but technically it is so small, that one can define one function $f_{\mathrm{A}}$, where the subscript $\mathrm{A}$ generalizes over the labels $i d$ and su: for all $x, f_{\mathrm{A}}(x)=x+b$, where $o \leq b \leq 1$. This format accounts for verbs used in situations in which it is impossible to distinguish between stativity and nonstativity without more contextual information, as in hang, think, meander, see, prove, etc. The nonstative interpretation of The man hung on to the rope, for example, is not quite realistic if the man is dead (so $b=o$ ), whereas it is plausible in an acrobat's act $(o<b \leq 1)$.

Semantically, the information about whether a verb is stative or not is located in the index $\alpha$ serving as an argument for the verb, as shown in (3). The variable $\alpha$ is the range of the function $i d$ or $s u$.

(3) a. $\mathrm{V}(\alpha)(x) \& \alpha=\operatorname{Ran}(i d)$ or $\mathrm{V}(\alpha)(x) \& \alpha=\operatorname{Ran}(s u)$

b. $\mathrm{V}(\alpha)(y)(x) \& \alpha=\operatorname{Ran}(i d)$ or $\mathrm{V}(\alpha)(y)(x) \& \alpha=\operatorname{Ran}(s u)$

In that sense, the format of the predicate-logical representation of a verb with an external argument $x$ in (3a) and of a verb with an external argument $x$ and an internal argument $y$ in ( $3 \mathrm{~b}$ ) does not deviate from the format used in event semantics as developed in Davidson (1967), where the main predicate in (3a) would be written as $\mathrm{V}(e)(x)$. The difference is that the variable $\alpha$ in (3) is made strictly atemporal by having a numerical value. Representation (3a) accounts for the sing- and sail-examples of Figures 1 and 2. For verbs like discover and eat, (3b) will do the job, as discussed in $\S 4 .^{6}$

The two $\mathbb{R}^{+} \rightarrow \mathbb{R}^{+}$-functions id and $s u$ are strictly lexical. For verbs without an internal argument and expressing discretization lexically, Verkuyl (2019) defined the generalized ceiling function $g c$ mentioned earlier.

(4) $V(\alpha)(x) \& \alpha=g c(\operatorname{Ran}(s u))$

Its input is $\operatorname{Ran}(s u)$, its range is a subset of $\mathbb{N}$ minus the property of equidistance between natural numbers. While represented in $\mathbb{N}$, a verb remains 'anchored' in

6. For type-logical reasons, the standard format for expressions like $\mathrm{V}(x, y)$ in first order logic is written here as $\mathrm{V}(y)(x)$ which does more justice to the compositionality of phrase structure. 
$\mathbb{R}^{+}$, as illustrated in Figure 3. This provides the warrant that information about $A_{c}$ remains saved at the level of $\mathbb{N}$. After all, discretization is a form of representing more complex information temporarily or definitely in terms of a unit counted as a point value in $\mathbb{N}$.

The function $g c$ operating on $s u$ provides information about the cardinality of $\alpha$, as shown in (5).

(5) $V(\alpha)(x) \& \alpha=g c(\operatorname{Ran}(s u)) \&|\alpha| \geq 1$

The clause $|\alpha| \geq 1$ in (5) holds for any gcosu-verb. It turns the idea of an inherent telos expressed by verbs like explode, die, collapse, etc. into a misleading misinterpretation of what a verb stem expresses lexically. A verb like erupt expresses no telos, unless this notion is so diluted that it can mean anything. Due to the lexical specification of erupt in terms of a composite function $g c^{\circ} \mathrm{su}$, the verb expresses an unbounded discretely organized series $A_{d}$. This means that the verb can be used both in situations in which $|\alpha| \geq 1$ and in situations in which $|\alpha|=n$. It is tempting to think of the verb erupt that the eruption described in (6a) pertains to a unique irrepeatable event, but this temptation is suggested by the default interpretation of the English past tense rather than by the lexical meaning itself.

(6) a. The Vesuvius erupted in $\mathrm{AD} 79$.

b. Violence erupted in Chicago in 1968.

c. For weeks and weeks violence erupted in Chicago in 1968.

Even a default requirement is not sufficient: (6a) - (6c) all express unboundedness (in $\mathbb{N}$ ) so it is only specific contextual information that may restrict $|\alpha| \geq 1$ to $|\alpha|=1$, not the past tense form. Sentence (6a) does not give away whether it is about one eruption or about a series of eruptions in $\mathrm{AD} 79$, archeologists must tell us. This can only be explained on the assumption that the verb erupt pertains to a series structured as in Figure 3. Due to the durative "leakage" in the external argument violence in (6b), there is no way to bound the series. Even the temporal adverbial in 1968 does not suffice for reducing $A_{d}$ to a (terminative) singleton, as illustrated by $(6 \mathrm{c})$.

For transitive $s u$-verbs, with two arguments $y$ and $x$ as in (7), the application of the rounding off function $g c$ is lexical (discover, hit, win, etc.) or it is triggered by information at the phrasal level contributed by the internal argument as in eat a sandwich, walk a mile, write three letters, etc. (for the details of the latter application, see Verkuyl (2019).

(7) $\mathrm{V}(\alpha)(y)(x) \& \alpha=g c(\operatorname{Ran}(s u)) \&|\alpha|=n$

The last clause in (7) requires boundedness as shown in (8a) and (8b), in which $m$ is a natural number greater than 1 determined contextually. 
(8) a. John discovered a treasure. $(|\alpha|=1)$

b. John discovered some treasures. (there is an $m, 1<|\alpha| \leq m$ )

c. John discovered treasures. $(|\alpha| \geq 1)$

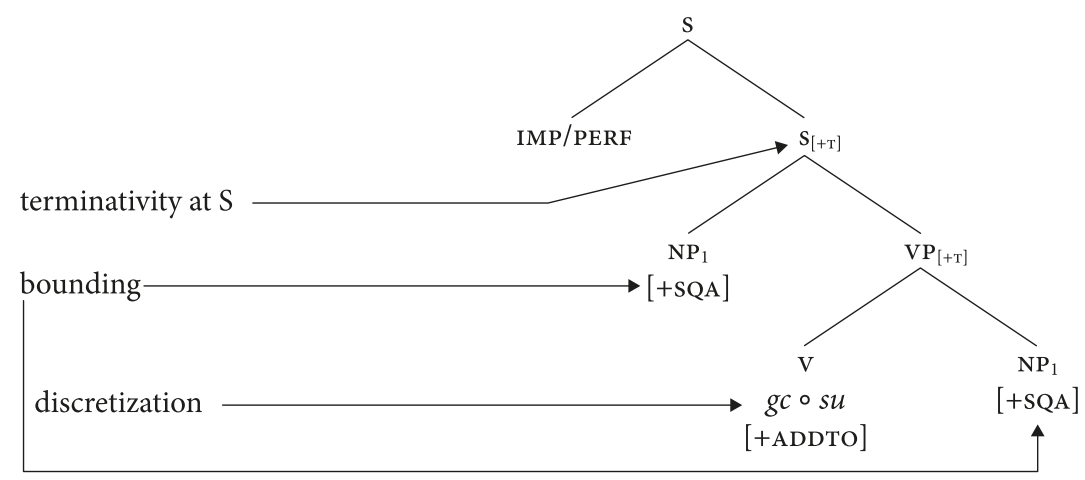

Figure 4. Tenseless aspectual composition

Figure 4 illustrates the Plus-principle which says that bounding by arguments can only be achieved (i) if they contribute a specified quantity of the head noun denotation A, abbreviated as [+SQA], a value which pertains to the cardinality information contributed by a treasure in (8a) and by some treasures in (8b); and (ii) if $\mathrm{V}$ has a [+ADDTO]-value, i.e. counts as a nonstative verb defined by $s u$. The resulting predication is then terminative (abbreviated as $[+\mathrm{T}]$ ). One minus feature in the lower $\mathrm{S}$ suffices to make the tenseless predication durative either as a continuous line in $\mathbb{R}^{+}$or as a series of points in $\mathbb{N}$ representing intervals, as illustrated in (6) and (8c). ${ }^{7}$ For verbs like discover, the bare plural treasures in $(8 \mathrm{c})$ contributes the cardinality information $|\alpha| \geq 1$ which cannot restrict the unboundedness in $\mathbb{N}$. This demonstrates the importance of letting a verb express leniency: it may apply to a series of discover-intervals of the type illustrated in Figure 3 and so it allows the adverbial for weeks to express unboundedness in $\mathbb{N}$.

It is easy to be led into the conviction that $(8 \mathrm{a})$ corresponds $1: 1$ to the structure dominated by $\mathrm{S}_{[+\mathrm{T}]}$ so that after all one has a case where discover is bound to pertain to just one actualization which would make an end to the Galilean story. But

7. For the details of the Plus-principle, see Verkuyl (1993). Features are just abbreviations. The formal details of the compositionality involved in (8) are given in Verkuyl (2019). In (8b), the $\mathrm{VP}$ is bounded due to the cardinality $|y|=1$ of the [+SQA]-NP $a$ treasure. This requires the clause $1 \leq|\alpha| \leq|y|$. In (8c), the VP is bounded by the fact that some treasures requires there to be a number $m \in N$ such that $|\alpha| \leq|m|$. In (8a), the VP is unbounded in $\mathbb{N}$ : the bare plural [-SQA]-NP treasures is not able to restrict $\mathbb{N}$ to a finite subset. 
(8a) is not what is being discussed here in terms of the Plus-principle: below $S_{[+\mathrm{T}]}$ all sentences in (8) are still tenseless, so the question is whether in the case of (8a) the tenseless John discover a treasure denotes a unique actualization. It is easy to see that Every month John discovered a treasure is about as many treasures and treasure findings as there were months in the period the sentence is about. This means that one has to wait until the top of the tensed sentence (8a) is reached after the application of PAST before one may begin to think about a unique actualization of a discrete treasure finding by John. This point will come back in more detail in $\S 4$ where the contribution of PERF and PAST to boundedness and actualization will be investigated. Due to the infinitival form of the verb the level of terminativity is still too low for unique actualization.

Summarizing, the Aristotelian notion of movement requiring a telos can be argued to be inferior to the Galilean notion of ([+ADDTO]-)movement, which is infinite unless it is blocked. It would therefore be misleading to try and relate the quadripartition in Table 1 to the four Vendler classes or to the three classes States, Processes and Events in Mourelatos (1981).

Table 1. Crossing two distinctions

\begin{tabular}{lcc}
\hline & Continuous: $A_{c}$ & Discrete: $A_{d}$ \\
\hline nonstative & + & + \\
stative & + & - \\
\hline
\end{tabular}

In all four cells, verbs express unboundedness of $A_{c}$ and $A_{d}$ at the level of $\mathrm{S}_{[+\mathrm{T}]}$. As will be argued in $\S 4$, tense information located higher than $S_{[+T]}$ is a necessary (but not sufficient) condition for getting just one unique full actualization or to a unique series of full actualizations.

\section{Connecting tense and aspect}

In Figure 4, IMP or PERF takes $S_{[+T]}$ so as to form a higher tenseless $S$ which is the input of an operator of the second binary opposition, (SYN or POST. This yields a tenseless $\mathrm{S}$ taken by the PRES- or PAST-operator so as to form the resulting tensed sentence S. In Figure 5, a choice for PERF, SYN and PRES yields (9a).

In (9b), of these three only PERF occurs, so (9a) should in fact be read as John have discovered three treasures and (9c) as Mary sail on the North Sea without a permit. The index $k$ in $(9 \mathrm{~b}, \mathrm{~d})$ substitutes for the lexical variable $\alpha$ dealt with in the preceding section. 


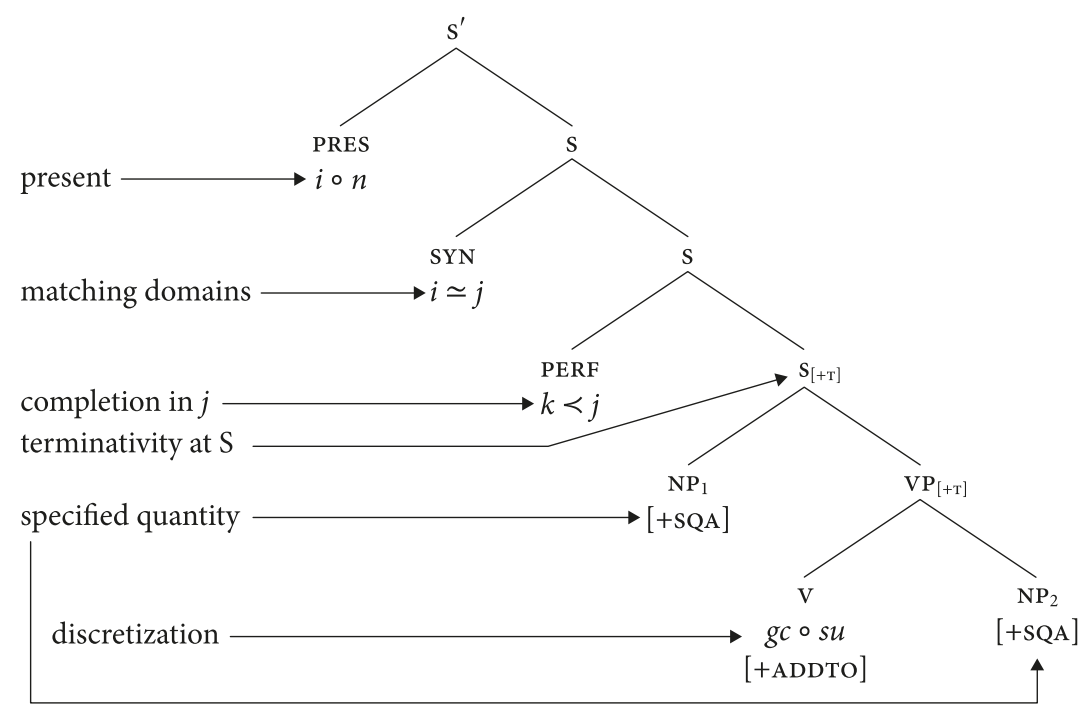

Figure 5. Aspectual composition in John has discovered three treasures

(9) a. John has discovered three treasures.

b. $\mathrm{V}(k)(x) \& k=g c(\operatorname{Ran}(s u))$ \& $k<j$

c. Mary sailed on the North Sea without a permit.

d. $\quad \mathrm{V}(k)(x) \& k=\operatorname{Ran}(s u) \& k \leqslant j$

Both IMP and PERF introduce a connective relating $k$ to $j$. In a binary approach, tense is to be seen as a way to connect the present domain $i$ of speaker and hearer to a domain $j$ in which $k$ is located either leaving the hearer underinformed about complete actualization $(k \leqslant j)$ or as explicitly informed about its full actualization in $j(k<j)$.

In English, the clause $k<j$ in $(9 b)$ is introduced by the use of the auxiliary have. It expresses that $k$ is to be actualized fully in $j$. The clause $k \leqslant j$ in (9d) expresses the uncertainty about whether $k$ is completed in $j$ due to the absence of have. Uncertainty is essential to the tenseless IMP. This follows from the nature of the opposition between PERF and IMP which is a privative one. The PERF-operator is the marked one, whereas IMP is unmarked and covers different interpretations, as in (9c) which may be followed by $\cdots$ this morning, . -last week but also by for years. So rather than saying that IMP has two meanings, one should say that it expresses underinformation about which of these possible interpretations applies, until contextual information provides some certainty. If (9c) expresses completion 
of Mary's sail then this is due to the anteriority relation between a past domain $i$ and the present domain $i$ evoked by the tense operator PAST. ${ }^{8}$

Representation (9b) accounts for the tenseless $S$ formed by PERF and $S_{[+T]}$. as part of the binary tense system in which unique actualization in the real time of the domain of interpretation can only be achieved by applying PAST or PRES. This is because by the choice of a finite tense form speaker and hearer locate an eventuality with respect to their own present domain $i$. The operator SYN is defined as connecting the present domain $j$ of $k$ synchronously to what speaker and hearer experience as their present domain $i$ in their use of present tense forms. ${ }^{9}$ Figure 5 shows that this happens at the level of the application of syn by the clause $i \simeq j$, which says that $i$ and $j$ are synchronous at the highest level S'.

The PRES-operator is defined as containing the fleeting point $n$, by the clause $i \circ n$. In a tripartition Past-Present-Future the point $n$ is generally taken as the Present ( $=$ the point 'now'). In a binary approach the floating $n$ is that part of the present domain $i$ that splits $i$ into an actualized part and an unactualized part.

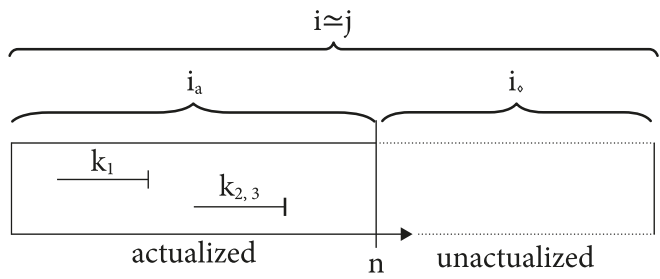

Figure 6. John has discovered three treasures (first one, then two)

Figure 6 captures the situation in which (9a) is about John who first discovered one treasure and later on two at the same time. This is just one of many more possibilities expressed by (9a). Hence it is impossible to chacterize discover lexically as pertaining to just one event.

The PAST-operator locates all information of the $S$ immediately below the $S$ ' of Figure 5 in a past domain $i$, so that $j$ and hence $k$ are located in $i$. They are (only indirectly) connected to $i$ by the anteriority clause $i<i$. The use of He discovered three treasures as part of a story about John, assumes a past domain $i$ anterior to

8. English deviates here from other Germanic languages (at least Dutch) where the anteriority relation expressed by PAST does not overrule IMP.

9. There is no room for treating the POST-operator here, but see Broekhuis and Verkuyl (2014) for an extensive treatment. 
$i$, that is, $i<i$, in which the then-present domain $j$ of $k$ is located..$^{10}$ The use of different connectives marks the difference between PAST+IMP and PRES+PERF.

All in all, there appear to be quite diverse factors involved in the aspectual composition of tensed sentences expressing completion:

a. the composite lexical function $g c \circ s u$ provides an unbounded sequence $\{1,2,3, \ldots\}$, possibly restricted by contextual information (arguments, adverbials, etc.);

b. [+SQA]-arguments yield a necessary condition for the quantificational part of bounding the sequence introduced by the verb;

c. terminativity at $S$ is achieved by having only plus-features;

d. PERF requires complete actualization of $k$ in $j$ by $g \cos u$;

e. PREs locates the clause $k<j$ in its actualized part. ${ }^{11}$

Figure 5 represents just one of the eight tenses in English that may occur with the tenseless predication John discover three treasures. The English PAST in (8a) John discovered a treasure expresses anteriority by $i<i$ with a default instruction to interpret $k \leqslant j \& j \simeq i \& i<i \&$ i॰n as requiring that $k \leqslant j$ be read as $k<j$ in $i$ unless the context tells differently. I will not go into any of the six remaining tenses in the same way here because that would not add to the maint point at issue in the present section: the division of labour between tense and aspect in the strict compositional way of bringing together the elements that have to be composed.

Figure 5 should also make it clear that there are three sorts of restriction on the unboundedness expressed by infinitival forms of a nonstative verb.

1. "blocking"-restrictions on the unbounded continuity or periodicity of a nonstative verb expressed by the [+SQA]-arguments;

2. the full actualization restriction expressed by PERF requiring completeness in $j$;

3. the anteriority restriction by locating $k$ and $j$ in a past (i.e. then-present) domain $i$ which is anterior to the present domain $i$ of speaker and hearer.

These restrictions are of a different nature. As observed above, they are not always sufficient for obtaining the situation in which one is for $100 \%$ sure about the unique actualization of the eventuality spoken about in the real time construed by the speaker/hearer in their present domain $i$.

10. For the details of this remarkable parallelism between Past and Present in a binary tense system, see Verkuyl (2008).

11. Dutch allows for locating $\mathrm{k}<\mathrm{j}$ in the non-actualized part of $\mathrm{i}$ (cf. Verkuyl 2008,pp. 67-72). 
The IMP/PERF-level seems to me a level important for comparative L2-research. Germanic languages use the auxiliary have to express PERF, whereas Russian PERF uses a perfective prefix and Mandarin-Chinese particles. It is also the level at which in Romance languages a battle is going on between the Present Perfect and aoristlike tense forms, the Pretérito in Spanish and the Passé Simple in French. As argued in González and Verkuyl (2017), Figure 5 expels the peninsular Spanish Pretérito from the binary part of its rich tense system because it is basically a specific anterior form outside the range of the IMP/PERF-opposition and insensitive to the opposition between durative and terminative at the level of the lowest $\mathrm{S}$ in Figure 5. For L2-research it is important to decide whether or not one has to see as the level at which the terms Perfective and Perfect are exchangeable or not. For languages with rich tense systems such as the Romance languages it is tempting to see the aorist in terms of perfective aspect. However, as soon as an aorist-like form obtains the status of outsider by being banned from participating in the binary oppositions that characterize the kernel of the system, one might reconsider the use this term by seeing the Spanish Préterito and the Passé Simple as tense forms expressing double anteriority, i.e. locating something in the past of what already has been located in a Past domain. Rather than as presenting something as completed, completion may be simple inferred. The position of a Pluperfect in a binary tense system predicts the superfluity of an aorist form.

\section{Vendler and the Imperfective Paradox}

As a philosopher Vendler must have been familiar with standard translations of Metaphysics 1048a, b, Ross in Aristotle (1924) and Tredennick in Aristotle (1933). Both use the Progressive Form (ProgF) where Greek (but also French, Spanish, Dutch, German, etc.) use the Present tense form. Unfortunately these translations are wrong and misleading for linguistic research into tense and aspect, as argued in detail in Verkuyl (in prep.). The question at issue is whether the Greek IMP expresses what is being expressed by the English PROG. It is an important question because Vendler uses the feature [+PROG] as crucial for distinguishing two of his classes, Activities and Accomplishments, and [-PROG] as distinctive for the two other classes, States and Achievements. This bears directly on the foundation of the LAH.

The question is to be answered negatively as soon as the opposition between IMP and PERF is taken privatively, with PERF as the marked member. This means that the connective ' $\leqslant$ ' used here for defining IMP should be read as 'not perfect(ive)' giving away that one is underinformed about the options (i) ' $k=j$ ' and (ii) ' $k<j$. Further information is necessary to decide which option is the appropriate 
one. It is inherent to IMP to express uncertainty about which option is to be taken. It follows that one cannot use the term Imperfective Paradox for the requirement that a Progressive Form explicitly express the impossibility of $k<j$. By doing so, an essential property of IMP - underinformation - is ignored.

That the Progressive Form is not an IMP-form can be clarified by comparing (10a), discussed in Dowty (1977), with the Dutch translation of the English IMP-sentence (10c) in (1ob).

(10) a. John was drawing a circle.

b. John drew a circle.

c. John tekende een cirkel.

Dowty treats BE - ING as a tense operator PROG (for him an IMP-operator) operating on the verb draw or possibly the VP draw a circle. But drawing is an untensed form. The PAST-operator in (10a) operates on the copula be and due to the absence of have in John be drawing a circle, the input to PAST is the IMP-predication John be drawing a circle. Now, as argued in Verkuyl (2019) and González and Verkuyl (2017), -ing can be seen as a suffix operating on the infinitival form of draw. As an operator on V, ING operates on the index $\alpha$ of draw. The copula $b e$, being a verb occurring in the lexicon, has its own index $\alpha$. In the construction be drawing, the $\alpha$ ' of be is the main index because it receives tense. This means that the ING-operator in $\mathrm{BE}(\mathrm{ING}(\mathrm{V}(\alpha)($ a circle $)(\mathrm{John})))$ can be understood as defining the relation between $\alpha$ and $\alpha$. In simplified notation ING requires: $\alpha=\alpha{ }^{12}$ Because $\alpha$ is the index of the stative verb be, the terminativity of the construction draw a circle having $\alpha$ as its verb-index cannot be completely obtained. ${ }^{13}$ This happens below the level of $\mathrm{S}_{[+\mathrm{T}]}$ in Figure 5 , so that the V-ing

12. Here the simple equation suffices to indicate the identity of some property of $\alpha$ with some property of $\alpha$. The notation has been simplified here for reasons of understandability. In a more formal type-logical setting, one should read $|\alpha|=\left|\alpha^{\prime}\right|$ because the equation pertains to function values. Functions can be seen as sets of pairs and these sets have a cardinality. For formal details of the ProgF-analysis, see Verkuyl (2019).

13. For this reason Comrie's well-known description of the opposition between perfective and imperfective aspect as paying "essential attention to the internal structure of the situation" (1976,p.16) might follow from his being a native speaker of English applying the narrow meaning of the Progressive in characterizing the broader notion of imperfective aspect in Slavic. Imperfective aspect covers a lot of different uses of imperfective verbs as pointed out clearly e.g. in Borik (2006) and so Jakobson's characterization of the main aspectual opposition as a privative one should be preferred. 
part of the English Progressive Form cannot be taken as an IMP-form at all. The IMP-form of (10a) works on the verb $b e .{ }^{14}$

Dutch has (10c) fully available as the literal counterpart of the English IMP-sentence (10b). The difference between the (1ob) and (10c) is simply a difference between the strength of the anteriority relation $i<i$. By the availabilty of the Progressive Form and the prominent place of this form in English, the default value for separating the past domain $i$ from the present domain $i$ by the clause $i<i$ is much higher in English than in Dutch, where a construction comparable to (10a) exists but is used marginally. Consequently, the Dutch default is to use the $k \leqslant j$-clause of IMP for underinformation. A pleasant consequence of splitting PROG into BE and ING is that it offers a natural explanation for the fact that the Progressive Form is not very inviting to verbs expressing states. If ING indeed does as described above (see also footnote 12), namely to prevent the application of $g c$ by making the nonstative function $s u$ dependent on the stative verb be, then it follows that it hardly makes sense to make a state dependent on a state.

\section{Some conclusive remarks}

In view of the preceding sections, some conclusions with respect to the four points defining the LAH in $\S 1$ can be drawn. Point 4 can be dropped in view of $\S 5$. A reformulation of point 3 eliminating Vendler classes would amount to the prediction that She was walking is learnt earlier than She was walking home and He was winning earlier than He was winning the battle against inflation. It seems to me that this is not what Andersen had in mind when he stated the LAH.

As to points 1 and 2, one has to take into account that the Spanish Pretérito and the French Passé Simple are not perfect(ive) forms but rather quite specific anterior forms in the periphery of the Spanish tense system, as argued in González and Verkuyl (2017), and of the French tense system, as argued in Verkuyl (2008). When speakers learning Spanish as L2 acquire the morphological marking of the Pretérito before they acquire the morphological marking of the Imperfecto, this seems rather a matter of acquiring a specific form of anteriority, at least in the pensinsular Spanish where the Pretérito is on its way to a specific niche, comparable with the retreat of the Passé Simple in French.

14. For a more detailed analysis of the Spanish Progressive Form, see González and Verkuyl (2017, pp. 24ff.). Arche (2014, pp. 797-810) also separates the contribution of the copula from that of the present participle, but she does so in a more syntactic ternary framework not working with the restrictive relation between two verb indices. 
In the binary system discussed here, the anteriority of the Imperfect is characterized by the clause $i<i$, which means that the PAST-operator makes the past domain $i$ directly related to the present domain $i$ of speaker/hearer. The Pretérito in Spanish can be seen as locating an eventuality index $k$ anterior to another eventuality index $k^{\prime}$ already introduced in the past domain $i$ as explained in $\S 4$. This predicts that there is no difficulty in obtaining the Pretérito in a durative sentence like Lucía cantó earlier than the terminative Lucía cantó esa aria. Actually, this would even be more probable given the fact that in didactic grammars learners learn simple verb forms before they get to more complex ones and to phrases. But apart from that prediction: points 1 and 2 do not make sense as long as the implicit opposition PERF (in 1) vs IMP (in 2) is maintained: the factual PERF/IMP opposition in Spanish is the one between the Pretérito perfecto compuesto and the Pretérito pluscuamperfecto on the PERF-side and the Presente and the Pretérito imperfecto on the IMP-side. If the Pretérito has found a niche it is an outmoded anteriority niche in the sense that it does not relate to the present domain iof speaker and hearer but rather to some contextual point of departure.

My unfamiliarity with experimental L2 research is prohibitive in charting the consequences of reformulating the LAH in compositional terms along the line followed above. Perhaps the results of many of the experiments checking the LAH in the past decennia turn out to even gain from such a reformulation. In the joint paper with Paz González announced, we will go through the relevant L2-literature in order to see whether or not the original intention of the LAH can be done justice in terms of the present theoretical considerations.

\section{Acknowledgements}

I would like to thank Paz González and Tim Diaubalick as well as two anonymous reviewers for their comments

\section{References}

Andersen, R.W., \& Shirai, Y. (1996). The primacy of aspect in first and second language acquisition: The pidgin/creole connection. In W.C. Ritchie, \& T.K. Bhatia (Ed), Handbook of Second Language Acquisition (pp. 527-570). Academic Press, New York.

Arche, M. J. (2014). The construction of viewpoint aspect: the imperfective revisited. Natural Language and Linguistic Theory, 32(3), 791-831. https://doi.org/10.1007/s11049-013-9209-5 Aristotle (1924). Metaphysics. In J. Barnes (Ed.), The complete works of Aristotle. The Revised Oxford Translation, volume II (pp. 1552-1728). Oxford: Clarendon Press. Translated by W.D. Ross. Also via: www.perseus.tufts.edu/hopper 
Aristotle (1933). Metaphysics. In Aristotle. Aristotle in 23 Volumes, volume 17, 18. William Heinemann LTD/Harvard University Press, London/Cambridge MA. [ed. 1989]. Translated by Hugh Tredennick. Also via: www.perseus.tufts.edu/hopper

Binnick, R.I. (Ed.) (2012). The Oxford handbook of tense and aspect. Oxford: Oxford University Press. https://doi.org/10.1093/oxfordhb/9780195381979.001.0001

Borik, O. (2006). Aspect and reference time, volume 13 of Oxford Studies in Theoretical Linguistics. Oxford and New York: Oxford University Press. https://doi.org/10.1093/acprof:oso/9780199291298.001.0001

Broekhuis, H. \& Verkuyl, H. J. (2014). Binary tense and modality. Natural Language and Linguistic Theory, 32, 1-34. https://doi.org/10.1007/s11049-013-9213-9

Comrie, B. (1976). Aspect. Cambridge textbooks in linguistics. Cambridge: Cambridge University Press.

Davidson, D. (1967). The logical form of action sentences. In N. Rescher (Ed.), The logic of decision and action (pp. 81-120). Pittsburgh: University of Pittsburgh Press.

Dowty, D. (1977). Towards a semantic analysis of verb aspect and the English imperfective progressive. Linguistics and Philosophy, 1, 45-77. https://doi.org/10.1007/BFo0351936

Dowty, D. (1979). Word meaning and Montague grammar. The semantics of verbs and times in generative semantics and in Montague's PTQ, volume 7 of Synthese Language Library. Dordrecht: D. Reidel Publishing Company. https://doi.org/10.1007/978-94-009-9473-7 González, P., \& Verkuyl, H. J. (2017). A binary approach to Spanish tense and aspect: On the tense battle about the past. Borealis. An International Journal of Hispanic Linguistics, 6(1), 97-138. to obtain via URL: http://septentrio.uit.no/index.php/borealis/index

Kenny, A. (1963). Action, emotion and will. London, New York: Routledge \& Kegan Paul.

Mourelatos, A.P. (1981). Events, processes and states. In P.J. Tedeschi, \& A. Zaenen (Ed.), Syntax and semantics 14: Tense and aspect (pp. 191-212). New York: Academic Press. Slightly improved version of: Linguistics and Philosphy, 2, 1978, 414-434.

Prior, A. (1967). Past, present and future. Oxford: Oxford University Press. https://doi.org/10.1093/acprof:0so/9780198243113.001.0001

Reichenbach, H. (1947). Elements of symbolic logic. New York: The Macmillan Company. First free press paperback edition 1966 edition.

Rothstein, S. (Ed.). (1998). Events and grammar, volume 70 of Studies in Linguistics and Philosophy. Dordrecht, Boston, London: Kluwer Academic Publishers.

Ryle, G. (1949). The concept of mind. New York: Barnes and Noble.

Ryle, G. (1954). Dilemmas. The Tarner Lectures 1953. Cambridge: Cambridge University Press. Paperback edition 1969. https://doi.org/10.1017/CBO9781316286586

Salaberry, M. R. (2000). The development of past tense morphology in L2 Spanish. Amsterdam/Philadelphia: John Benjamins Publishing Company.

Salaberry, R. (2003). Tense aspect in verbal morpholog. Hispania, 86(3), 559-573. https://doi.org/10.2307/20062909

Smith, C.S. (1991). The parameter of aspect, volume 43 of Studies in Linguistics and Philosophy. Dordrecht: Kluwer Academic Publishers.

Vendler, Z. (1957). Verbs and times. The Philosophical Review, 66, 143-160. Also in: Z. Vendler Linguistics in Philosophy. Ithaca NY: Cornell University Press, 1966, ch. 4, 97-121.

Verkuyl, H.J. (1993). A theory of aspectuality. The interaction between temporal and atemporal structure, volume 64 of Cambridge Studies in Linguistics. Cambridge: Cambridge University Press. https://doi.org/10.1017/CBO9780511597848 
Verkuyl, H.J. (2008). Binary tense, volume 187 of CSLI Lecture Notes. Stanford, CA: CSLI Publications.

Verkuyl, H.J. (2019). Event structure without naive physics. In R. Truswell (Ed.), The Oxford Handbook of event structure (chapter 7, pp. 172-204). New York: Oxford University Press.

Verkuyl, H. J. (in preparation) On the Compositional Nature of Tense, Mood and Aspect. Book.

\section{Address for correspondence}

Henk J. Verkuyl

Utrecht University

Dutch, UIL OTS

De Lairessestraat 163 HS

1075 HK Amsterdam

Netherlands

h.j.verkuyl@uu.nl

(iD) https://orcid.org/oooo-ooo2-5943-4845

\section{Publication history}

Date received: 7 January 2019

Date accepted: 2 December 2019 